Published in final edited form as:

Sci Transl Med. 2017 April 05; 9(384): . doi:10.1126/scitranslmed.aai8711.

\title{
Therapeutic treatment of Marburg and Ravn virus infection in nonhuman primates with a human monoclonal antibody
}

\author{
Chad E. Mire ${ }^{1,2}$, Joan B. Geisbert ${ }^{1,2}$, Viktoriya Borisevich ${ }^{1,2}$, Karla A. Fenton ${ }^{1,2}$, Krystle N. \\ Agans $^{1,2}$, Andrew I. Flyak ${ }^{3}$, Daniel J. Deer ${ }^{1,2}$, Herta Steinkellner ${ }^{4}$, Ognian Bohorov ${ }^{5}$, \\ Natasha Bohorova ${ }^{5}$, Charles Goodman ${ }^{5}$, Andrew Hiatt ${ }^{5}$, Do H. Kim ${ }^{5}$, Michael H. Pauly ${ }^{5}$, \\ Jesus Velasco ${ }^{5}$, Kevin J. Whaley ${ }^{5}$, James E. Crowe Jr. ${ }^{3,6,7}$, Larry Zeitlin ${ }^{5, \dagger,}{ }^{*}$, and Thomas W. \\ Geisbert ${ }^{1,2, \dagger,{ }^{*}}$ \\ ${ }^{1}$ Galveston National Laboratory, University of Texas Medical Branch, Galveston, TX 77555, USA \\ ${ }^{2}$ Department of Microbiology and Immunology, University of Texas Medical Branch, Galveston, TX \\ 77555 , USA \\ ${ }^{3}$ Department of Pathology, Microbiology, and Immunology, Vanderbilt University Medical Center, \\ Nashville, TN 37232, USA \\ ${ }^{4}$ Department of Applied Genetics and Cell Biology, University of Natural Resources and Life \\ Sciences, 1190 Vienna, Austria \\ ${ }^{5}$ Mapp Biopharmaceutical Inc., San Diego, CA 92121, USA \\ ${ }^{6}$ Department of Pediatrics, Vanderbilt University Medical Center, Nashville, TN 37232, USA \\ ${ }^{7}$ Vanderbilt Vaccine Center, Vanderbilt University Medical Center, Nashville, TN 37232, USA
}

\section{Abstract}

\begin{abstract}
As observed during the 2013-2016 Ebola virus disease epidemic, containment of filovirus outbreaks is challenging and made more difficult by the lack of approved vaccine or therapeutic options. Marburg and Ravn viruses are highly virulent and cause severe and frequently lethal disease in humans. Monoclonal antibodies (mAbs) are a platform technology in wide use for autoimmune and oncology indications. Previously, we described human mAbs that can protect mice from lethal challenge with Marburg virus. We demonstrate that one of these mAbs, MR191-
\end{abstract}

\footnotetext{
${ }_{*}^{\dagger}$ Corresponding author. twgeisbe@utmb.edu (T.W.G.); larry.zeitlin@mappbio.com (L.Z.).

*These authors contributed equally to this work.

Author contributions: C.E.M., J.E.C., L.Z., and T.W.G. designed the experiments. O.B., N.B., C.G., A.H., D.H.K., M.H.P., J.V., and K.J.W. manufactured, tested, and released the mAb. J.B.G. and D.J.D. performed the guinea pig studies. C.E.M., J.B.G., D.J.D., and T.W.G. performed the NHP experiments and conducted the clinical observations of the animals. J.B.G., V.B., and K.N.A. performed the clinical pathology assays. J.B.G. performed the MARV and RAVV infectivity assays. V.B. performed the MR191-N neutralization and escape mutant assays. K.A.F. performed histological and IHC analysis of the data. H.S., K.J.W., and L.Z. contributed the reagents for this study. A.I.F. and J.E.C. determined and provided the sequences for the antibodies. C.E.M., J.B.G., V.B., K.A.F., K.N.A., A.I.F., D.J.D., O.B., N.B., C.G., A.H., D.H.K., M.H.P., J.V., K.J.W., J.E.C., L.Z., and T.W.G. analyzed the data. C.E.M., L.Z., and T.W.G. wrote the manuscript.

Competing interests: K.J.W. and L.Z. are the owners of Mapp Biopharmaceutical Inc., which develops mAb-based drugs. A.I.F. and J.E.C. are co-inventors on a patent applied for that includes claims about the human antibodies described in this paper. All other authors declare that they have no competing interests.
}

Data and materials availability: Reagents described here are accessible via material transfer agreement with Mapp Biopharmaceutical Inc. or UTMB. 
N, can confer a survival benefit of up to $100 \%$ to Marburg or Ravn virus-infected rhesus macaques when treatment is initiated up to 5 days post-inoculation. These findings extend the small but growing body of evidence that mAbs can impart therapeutic benefit during advanced stages of disease with highly virulent viruses and could be useful in epidemic settings.

\section{INTRODUCTION}

Within the Filoviridae family, Marburg marburgvirus contains two members, Marburg (MARV) and Ravn (RAVV) viruses. The viruses are transmitted by direct contact with blood, body fluids, and tissues of infected persons or animals [bats or nonhuman primates (NHPs)], and infection can result in high fever, headache, malaise, severe diarrhea, vomiting, and hemorrhagic symptoms. The mean case fatality rate of Marburg virus disease (MVD) outbreaks in humans since the first recognized outbreak in 1967 is about $80 \%$ (1). Concerns regarding natural outbreaks and weaponization of the virus (2) have made the development of medical countermeasures for MARV and RAVV high priorities.

Because of their high potency and specificity, as well as their clinical safety and efficacy record, monoclonal antibodies (mAbs) are an appealing platform technology for addressing the public health burden posed by viral infectious diseases such as MVD. With more than 45 mAbs approved by the U.S. Food and Drug Administration and European Medicines Agency (3), many of the manufacturing, formulation, and regulatory challenges of mAb drug development are well understood. The usefulness of antibodies, both naturally occurring and passively applied, has been evident for prevention and postexposure of viral infections for over a century $(4,5)$. However, it is only recently that evidence has accumulated for the efficacy of mAbs as therapeutics, even for highly virulent viral pathogens such as Nipah virus (6), Hendra virus (7), and Ebola virus $(8,9)$.

A variety of techniques have been used for therapeutic mAb discovery, including humanization of murine $\mathrm{mAbs}$, phage display, and immunization of transgenic mice containing human immunoglobulin loci (10). One productive approach has been the isolation of human mAbs from survivors of infection (11-14), with an underlying rationale that naturally occurring $\mathrm{mAbs}$ obtained from human survivors are likely to have desirable safety and efficacy features based on B cell selection in vivo. We described previously a panel of human mAbs against the MARV glycoprotein (GP) generated from B cells of a survivor of MARV infection (15). All neutralizing mAbs from this panel bound to the same major antigenic site on the MARV GP (the receptor-binding site), and some were shown to cross-react with the RAVV GP. Here, down-selection of this panel of mAbs was performed using guinea pig models, and a lead therapeutic candidate was identified by efficacy testing in NHPs.

\section{RESULTS}

\section{Pilot study in guinea pigs}

Human mAbs against the MARV GP receptor-binding site have been observed to bind at three distinct angles of approach (15). Thus, three mAbs (MR78, MR82, and MR191), each 
representing a distinct binding angle, were selected for production in the Nicotiana benthamiana transient expression system (MR78-N, MR82-N, and MR191-N) (16) and subsequent testing in the lethal guinea pig-adapted (GPA) MARV and RAVV models (1719). For initial screening, guinea pigs received an intraperitoneal injection of 1000 plaqueforming units (PFU) of GPA MARV. Two days post-inoculation (dpi), treated animals received a 10-mg intraperitoneal dose of $\mathrm{mAb}$ (or about $20 \mathrm{mg} / \mathrm{kg}$ ). The dose used throughout these pilot studies was selected as a convenient dose consistent with dosing of the two mAbs approved by the U.S. Food and Drug Administration for infectious disease indications; palivizumab for respiratory syncytial virus is dosed at $15 \mathrm{mg} / \mathrm{kg}$, and raxibacumab for anthrax is dosed at $40 \mathrm{mg} / \mathrm{kg}$. MR82-N provided significantly less protection from death $(P<0.05$ by Mantel-Cox test) than MR78-N or MR191-N, which each provided $100 \%$ protection (fig. S1A). Virus could not be detected in plasma sampled 7 dpi in animals treated with MR78-N or MR191-N (fig. S1B), whereas virus was detected in the plasma of the control animal and each of the animals treated with MR82-N.

\section{Cross-protection study in guinea pigs}

To evaluate cross-protective efficacy in vivo and to further define the therapeutic window, we next tested MR78-N and MR191-N in GPA MARV- or RAVV-inoculated animals with a single 10-mg intraperitoneal dose of mAb $(\sim 20 \mathrm{mg} / \mathrm{kg}) 4 \mathrm{dpi}$. Sixty percent of MARVinfected animals treated with MR78-N and 100\% of animals treated with MR191-N survived (Fig. 1A); low levels of virus, about 1000-fold lower than controls, were detected in plasma 7 dpi in two MR78-N-treated animals $\left(5 \times 10^{1}\right.$ and $\left.2.2 \times 10^{2} \mathrm{PFU} / \mathrm{ml}\right)$ and one MR191-Ntreated animal $\left(1 \times 10^{2} \mathrm{PFU} / \mathrm{ml}\right)(\mathrm{Fig} .1 \mathrm{~B})$. All animals had an elevated body temperature, and about half experienced weight loss by 4 dpi (Fig. 1, C and D), suggesting therapeutic rather than postexposure prophylactic efficacy by the mAbs. All GPA RAVV-inoculated animals treated 4 dpi with either mAb survived (Fig. 1E), with no detectable circulating virus 7 dpi (Fig. 1F). In contrast, both control animals succumbed by $10 \mathrm{dpi}$ and had plasma viral loads of $1.3 \times 10^{5}$ or $1.4 \times 10^{5} \mathrm{PFU} / \mathrm{ml}$.

\section{Pilot study in NHPs}

On the basis of these guinea pig data, MR191-N was selected for advancement to a MARV NHP pilot study. Considering that initiation of treatment 3 dpi was the latest that any drug candidate had been shown to protect MARV-inoculated NHPs (20), it was decided to initiate MR191-N dosing 4 dpi. Briefly, NHPs were inoculated with MARV and then either treated $(n=3)$ with MR191-N (50 mg/kg) intravenously 4 and 7 dpi (table S1; MARV Tx-1-3) or received no treatment $(n=1$; table S1; MARV-1). All treated animals survived infection (Fig. 2A), whereas the control animal succumbed 8 dpi ( $P=0.093$ by Mantel-Cox test) and experienced severe clinical disease (Fig. 2, B and C, and table S1). Historical controls (20, $21)$ with this virus stock had a MTD of $7.9 \pm 0.6 \mathrm{dpi}(n=10 ; P<0.005$ compared with treatment group by Mantel-Cox test). On the first day of treatment 4 dpi, all NHPs were viremic and had an elevated body temperature (Fig. $2 \mathrm{D}$; average, $+0.5^{\circ} \mathrm{C}$; range, $+0.3^{\circ}$ to $0.8^{\circ} \mathrm{C}$ ). Treatment was associated with a decline in viral load by $7 \mathrm{dpi}$ with undetectable virus levels (limit of detection $=25 \mathrm{PFU} / \mathrm{ml}$ ) by $10 \mathrm{dpi}$. In contrast, the viral load in the control animal increased to almost $10^{8} \mathrm{PFU} / \mathrm{ml}$ by $8 \mathrm{dpi}$, the day the animal met clinical euthanasia criteria (Fig. 2B). 


\section{Cross-protection in NHPs}

To further define the therapeutic window of MR191-N, we performed a cross-protection study with dosing initiated 5 dpi. Groups of five animals were inoculated with an otherwise lethal dose of either MARV (Fig. 3) or RAVV (Fig. 4) and treated with MR191-N intravenously (table S1;MARVTx-4-8andRAVVTx-1-5)5and8dpi.Adoseof50mg/kg was chosen on the basis of dosing used in previous filovirus immunotherapy studies in NHPs ( 9 , 22). Eighty percent of MARV-infected $(P<0.05)$ and $100 \%$ of RAVV-infected $(P<0.05)$ NHPs survived, whereas the control animals succumbed on $8 \mathrm{dpi}$ (MARV) or $10 \mathrm{dpi}$ (RAVV). Compared to historical controls with the same viral stock, protection against MARV ( $P<0.005$; MTD of historical controls, $7.9 \pm 0.6 \mathrm{dpi} ; n=10)$ and RAVV $[P<0.01$; MTD of historical controls (23) $=9.0 \pm 1.7 \mathrm{dpi} ; n=3$ ] was highly significant (Figs. 3, A and $\mathrm{B}$, and 4, A and B). On day 5, before mAb treatment, MARV-infected NHPs had viral titers ranging from $8.3 \times 10^{3}$ to $3.8 \times 10^{5} \mathrm{PFU} / \mathrm{ml}$ by plaque assay (Fig. $3 \mathrm{C}$ ) and from $1.9 \times 10^{5}$ to $8.1 \times 10^{10}$ genome equivalents (GEQ)/ml by reverse transcription quantitative polymerase chain reaction (RT-qPCR) (Fig. 3D), as well as elevated body temperatures (average, $+0.8^{\circ} \mathrm{C}$; range, $+0.2^{\circ}$ to $1.6^{\circ} \mathrm{C}$; Fig. 3E). With the exception of MARV Tx-5, all MR191-Ntreated animals had undetectable levels of circulating virus by plaque assay and RT-qPCR by 11 dpi. MARV Tx- 5 experienced a drop in viral load by both assays and then experienced a viral rebound detected at 14 and 15 dpi when the animal met clinical euthanasia criteria. The gross pathology and immunohistochemistry after necropsy observed for this animal were consistent with disease caused by MARV (23), whereas tissues from MR191-N-treated animals exhibited no evidence of disease (fig. S2). To assess whether the viral rebound was due to an MR191-N escape mutant, we compared the neutralization activity of MR191-N on virus isolated $15 \mathrm{dpi}$ from MARV Tx-5 with the neutralization activity against the original virus used to inoculate the animals. No difference was observed, suggesting that the rebound was not associated with the emergence of an MR191-N escape mutant (fig. S3). In addition, no evidence of escape was detected by deep sequencing the viral genomic RNA 15 dpi; only a small population of genomes with a silent mutation in the GP gene was detected (table S2).

Before mAb treatment, all RAVV-inoculated animals had viral loads of $2 \times 10^{2}$ to $3 \times 10^{4}$ $\mathrm{PFU} / \mathrm{ml}$ by plaque assay $5 \mathrm{dpi}$ (Fig. 4C) and $1 \times 10^{6}$ to $1.2 \times 10^{8} \mathrm{GEQ} / \mathrm{ml}$ by RT-qPCR (Fig. $4 \mathrm{D}$ ), and five of six NHPs had an elevated body temperature (average, $+0.5^{\circ} \mathrm{C}$; range, $+0.1^{\circ}$ to $0.8^{\circ} \mathrm{C}$; Fig. 4E). Virus was not detected in MR191-N-treated animals by plaque assay from 8 dpi and by RT-qPCR from 11 dpi to the end of the study. The RAVV-infected control NHP had a peak viral load of $5.2 \times 10^{6} \mathrm{PFU} / \mathrm{ml}$ and $4 \times 10^{10} \mathrm{GEQ} / \mathrm{ml}$ on $8 \mathrm{dpi}$, the day the animal met clinical euthanasia criteria. The gross pathology and immunohistochemistry after necropsy observed for this animal were consistent with disease caused by RAVV (23), with no evidence of disease in treated animals (fig. S4).

The clinical data illustrate that mAb therapy, regardless of inoculated virus, reduced observed clinical illness compared to controls (table S1 and Fig. 3B). Nonetheless, MR191$\mathrm{N}$-treated NHPs had changes in hematology and blood chemistries indicative of MARV and RAVV infection, such as reduced lymphocyte counts and elevated liver enzymes. Unlike in the control animals, the clinical pathology changes resolved after MR191-N treatment resulted in reduced viral load, with the exception of MARV Tx-5. 


\section{DISCUSSION}

After multiple reports of an absence of benefit from antibody administration to NHPs infected with filoviruses (24-26), a seminal study by Dye et al. demonstrated that antibodies in the form of a concentrated polyclonal antibody preparation could affect survival of infection with EBOV or MARV in NHPs when treatment was initiated up to 2 dpi (27). Here, this initial finding has been extended to the use of a single recombinant $\mathrm{mAb}$ capable of protecting NHPs against both MARV and RAVV when given as late as 5 dpi. MR191 neutralizes cell-free virus weakly, with a median inhibitory concentration of $\sim 100 \mu \mathrm{g} / \mathrm{ml}$ for MARV (15) and $>1000 \mu \mathrm{g} / \mathrm{ml}$ for RAVV (15). This disparity between potency in vitro and efficacy in vivo suggests either an artifact associated with the standard MARV and RAVV neutralization assays or that neutralization may only be one of the mechanisms of action by MR191. Most recombinant mAbs and antibodies produced in vivo are fucosylated; afucosylated mAbslike MR191-N have enhancedbinding to Fc $\gamma$ RIII receptors compared to fucosylated mAbs, which can translate to enhanced antibody-dependent cellular cytotoxicity activity, theoretically increasing the ability of the mAb to facilitate killing of infected cells by the host immune system (28).

Although it is impossible to determine with certainty why MARV Tx-5 was the only MR191-N-treated NHP to succumb to infection, the data suggest that it was not due to selection of an escape mutant to the mAb. Notably, MARV Tx-5 had the highest viral load of any of the animals before treatment with mAb. Further, the serum concentration of MR191$\mathrm{N}$ in MARV Tx-5 was 10- to 100-fold less than that in the other NHPs $8 \mathrm{dpi}(50 \mu \mathrm{g} / \mathrm{ml}$; before receiving the second dose) and 2 - to 6 -fold less $14 \mathrm{dpi}(70 \mu \mathrm{g} / \mathrm{ml})$. These findings, together with the observation of high viral loads in circulation $\left(>10^{7} \mathrm{PFU} / \mathrm{ml}\right.$ and $>10^{11}$ $\mathrm{GEQ} / \mathrm{ml}$ ) and reported in liver and spleen tissue (20) during the course of MARV infection, are consistent with the hypothesis that insufficient concentration of MR191-N was present in MARV Tx-5. The emergence and selection of escape mutant viruses during in vivo treatment are general concerns with mAb therapeutics, but the occurrence of these depend highly on the specifics of the mAb and its epitope, as well as the nature of the infectious agent. Cocktails of mAbs are a strategy to minimize the risk of escape mutants and are likely important for some indications, such as HIV immunotherapy, where the neutralizing epitopes have great diversity between viral clades. In other cases, one mAb may be sufficient; a single $\mathrm{mAb}$ has been shown to be an effective therapeutic in NHPs infected with Ebola virus (29), and the anti-respiratory syncytial virus neutralizing mAb palivizumab has been in widespread clinical use for over 15 years, with escape mutants having minimal clinical relevance (30). No evidence of escape mutants was detected in the single NHP (MARV Tx-5) that succumbed to infection; the conservation of the MR191 epitope among both members of $M$. marburgvirus suggests that it may be critical for viral fitness.

The work presented here has several limitations. The number of neutralizing human mAbs available for evaluation was limited, and, from that small number, resource constraints only allowed testing of three mAbs in vivo. Further studies may identify superior mAbs or combinations of mAbs. Measurement of viral load by plaque assay in these studies may be confounded by the presence of the neutralizing $\mathrm{mAb}$ in blood, which highlights the importance of testing by the orthogonal RT-qPCR method. Finally, pharmacology and 
toxicology testing, as well as manufacturing under Good Manufacturing Practices, will be required before MR191 can be tested clinically.

The 2013-2016 Ebola virus disease epidemic highlighted the troubling absence of prophylactic or therapeutic options for filoviruses. Without a clinically acceptable treatment, little incentive exists for infected individuals to report to a treatment unit. This dynamic makes it difficult to track and contain outbreaks because infected individuals continue to expose family and community members to the risk of transmission. Recently, promising results in the MARV NHP model with potential medical countermeasures have been reported, including $100 \%$ protection of MARV-infected NHPs treated with seven daily doses of lipid-encapsulated small interfering RNA (siRNA) starting up to 3 dpi (20). Additionally, daily dosing for 14 days with an antisense phosphorodiamidate morpholino oligomer (PMO) starting 4 dpi provided 83 to $100 \%$ protection to NHPs infected with MARV-Musoke, a putatively less virulent MARV isolate $(1,31)$. The results reported here represent a significant advance in that a single drug candidate, MR191-N, provided therapeutic benefit against both MARV and RAVV with only two doses initiated 5 dpi. The observation that all treated animals were viremic before dosing suggests that this time frame is a clinically realistic treatment window. Although siRNAs and PMOs are both promising new classes of experimental molecules, the safety of mAb therapy in humans is well documented, particularly for mAbs against nonself antigens. mAbs offer the ability to confer immediate and specific immunity in all populations, including the young, the elderly, and the immunocompromised. The evidence presented here suggests that MR191 is an effective panmarburgvirus $\mathrm{mAb}$ and one of the most promising approaches in development for treating disease caused by MARV and RAVV.

\section{MATERIALS AND METHODS}

\section{Study design}

Guinea pigs were used to screen candidate MARV mAbs before assessment in NHPs ( $n=5$ guinea pigs per treatment group). A lead candidate mAb (MR191-N) was selected from the guinea pig studies for further evaluation in NHPs. Sixteen healthy adult rhesus macaques (Macaca mulatta) of Chinese origin (4 to $7 \mathrm{~kg}$ ) were used to conduct three separate studies to test the therapeutic efficacy of MR191-N. The experimental design included an initial study of three treated animals and one control animal to assess the efficacy against MARV when treatment was initiated 4 days after exposure. The two subsequent studies assessed the efficacy of MR191-N using groups of $n=5$ treated animals and $n=1$ control animal when treatment was initiated beginning 5 days after either MARV or RAVV virus exposure. Historical controls were used to supplement treatment groups. Animals were randomized with Microsoft Excel into treatment or control groups. A number of parameters were monitored during the course of the study, including survival, clinical observations, hematology, serum biochemistry, viremia and viral load in tissues by RT-qPCR and plaque assay, and tissue pathology. The primary objective of the study was to assess survival rates, with all other measurements being considered secondary objectives. This study was not blinded. Primary data are included in table S3. 


\section{mAb production}

mAbs [MR78 and MR82, human immunoglobulin G1 $\ltimes\left(\operatorname{IgG}_{1 \kappa}\right)$; MR191, human $\operatorname{IgG}_{1 \lambda}$ ] (15) used in guinea pig studies were produced in tobacco ( $N$. benthamiana) at Mapp Biopharmaceutical Inc., as described previously (32). mAbs used in NHP experiments were manufactured in $N$. benthamiana by Kentucky BioProcessing, as described previously ( 8 , 22). Consistent with previous findings (33-35), the mAb was $>99 \%$ afucosylated, with GnGn being the predominant N-glycoform, and significant differences were not observed between the lots produced at the two sites.

\section{Ethics statement}

Both the guinea pig and NHP research were conducted in compliance with the Animal Welfare Act and other federal statutes and regulations relating to animals and experiments involving animals and adhered to principles stated in the eighth edition of the Guide for the Care and Use of Laboratory Animals (National Research Council, 2011). The facility where this research was conducted [University of Texas Medical Branch (UTMB)] is fully accredited by the Association for Assessment and Accreditation of Laboratory Animal Care International and has an approved Office of Laboratory Animal Welfare Assurance (\#A3314-01). Conducting animal studies in biosafety level 4 (BSL-4) restricts the number of animal subjects, the volume of biological samples that can be obtained, and the ability to repeat assays independently and thus limits statistical analysis. Consequently, data are presented as means calculated from replicate samples, not replicate assays, and error bars represent SD across replicates.

\section{Guinea pig studies}

MARV mAbs were down-selected for use in NHPs using female outbred Hartley strain guinea pigs ( $\sim 350$ to $400 \mathrm{~g}$; Charles River Laboratories) that were inoculated with about 1000 PFU of GPA MARV (Angola isolate) or GPA RAVV by intraperitoneal injection (18). Three MARV mAbs (MR82-N, MR78-N, and MR191-N) (15) were tested therapeutically using a 10-mg intraperitoneal dose of individual $\mathrm{mAb}$ at $2 \mathrm{dpi}(n=5$ per antibody treatment) against GPA MARV inoculation, and two MARV mAbs, MR78-N and MR191-N, were tested at 4 dpi ( $n=5$ per antibody per virus) against GPA MARV or GPA RAVV inoculation. Animals were bled $7 \mathrm{dpi}$ and observed for signs of disease, weight loss, temperature, and survival up to 28 dpi.

\section{NHP studies}

Sixteen healthy rhesus macaques (M. mulatta) of Chinese origin (4 to $7 \mathrm{~kg}$ ) were used to evaluate MARV mAb MR191-N (50 mg/kg per dose) in three separate studies. In two studies, animals were inoculated by the intramuscular route with a target dose of 1000-PFU MARV Angola isolate Marburg virus H.sapiens-tc/ANG/2005/Angola \{passage 2; Vero E6 [American Type Culture Collection (ATCC), CRL-1586] $\}$ and were treated either at 4 and 7 dpi (control, $n=1$; treated, $n=3$ ) or at 5 and 8 dpi (control, $n=1$; treated, $n=5$ ); actual inoculum has $1050 \mathrm{PFU}$ for 4 or 7 dpi and $1240 \mathrm{PFU}$ for 5 or 8 dpi studies. In a separate study, NHPs were inoculated with RAVV Ravn virus H.sapiens-tc/KEN/1987/Kitum Cave-810040 (passage 3; Vero E6), 1000-PFU intramuscular target dose (actual dose, 1100 
PFU), and were treated at 5 and 8 dpi (control, $n=1$; treated, $n=5$ ). All animals were given physical exams, and blood was collected at the time of inoculation and on 4 or 5,7 or 8,10 or 11, 14, 21, and 28 dpi. In addition, all animals were monitored daily and scored for disease progression with an internal filovirus scoring protocol approved by the UTMB Institutional Animal Care and Use Committee. The scoring changes were measured from baseline for posture/activity level, attitude/behavior, food consumption (only the absence of food consumption is scored; incomplete consumption is noted as captured in table S1) and water intake, weight, respiration, and disease manifestations such as visible rash, hemorrhage, ecchymosis, or flushed skin. A set score of greater than 9 from combined signs was used to determine criteria for euthanasia.

MARV and RAVV seed stocks were deep-sequenced and compared to prototype isolates (GenBank \#DQ447653 and \#DQ447649) as described below. The challenge stocks were also tested for endotoxin in the preparations using the Endosafe-Portable Test System (PTS) (Charles River Laboratories). Virus preparations were diluted 1:10 in limulus amebocyte lysate (LAL) reagent water according to the manufacturer's directions, and endotoxin levels were tested in LAL Endosafe-PTS cartridges as directed by the manufacturer; each result was below the limit of detection, whereas positive controls showed that the tests were valid. Challenge stocks were also tested for mycoplasma contamination using the e-Myco PLUS Mycoplasma Detection Kit (Boca Scientific), and the results were found to be below the limit of detection.

\section{Detection of viremia by plaque assay}

Virus titration was performed on Vero E6 (ATCC, CRL-1586) cell monolayer cultures using a plaque assay, as previously described (36). Briefly, increasing 10-fold dilutions of the samples were adsorbed to Vero E6 monolayers in duplicate wells ( $200 \mu \mathrm{l})$, and, after 7 to 9 days, neutral red staining was used to visualize plaques; the limit of detection was 25 $\mathrm{PFU} / \mathrm{ml}$.

\section{Detection of viremia by RT-qPCR}

RNA was isolated from whole blood using Viral RNA Mini Kit (Qiagen) with $100 \mu \mathrm{l}$ of blood into $600 \mu \mathrm{l}$ of buffer AVL. Primers/probe targeting the nucleoprotein gene of MARV were used for RT-qPCR, with the probe used here being 6-carboxyfluorescein- $5^{\prime}$ CCCATAAGGTCACCCTCTT-3' -6-carboxytetramethylrhodamine (Life Technologies) (18). MARV RNA was detected using the CFX96 detection system (Bio-Rad Laboratories) in One-Step Probe RT-PCR kits (Qiagen) with the following cycle conditions: $50^{\circ} \mathrm{C}$ for $10 \mathrm{~min}$, $95^{\circ} \mathrm{C}$ for $10 \mathrm{~s}$, and 40 cycles of $95^{\circ} \mathrm{C}$ for $10 \mathrm{~s}$ and $59^{\circ} \mathrm{C}$ for $30 \mathrm{~s}$. Threshold cycle values representing MARV genomes were analyzed with CFX Manager Software, and data are shown as number of GEQ per milliliter. To create the GEQ standard, RNA from MARV stocks was extracted, and the number of MARV genomes was calculated using Avogadro's number and the molecular weight of the MARV genome.

\section{Hematology and serum biochemistry}

Total white blood cell counts, white blood cell differential counts, red blood cell counts, platelet counts, hematocrit values, total hemoglobin concentrations, mean cell volumes, 
mean corpuscular volumes, and mean corpuscular hemoglobin concentrations were analyzed from blood collected in tubes containing EDTA using a laser-based hematologic analyzer (Beckman Coulter). Serum samples were tested for concentrations of albumin, amylase, alanine aminotransferase, aspartate aminotransferase, alkaline phosphatase, $\gamma$ glutamyltransferase, glucose, cholesterol, total protein, total bilirubin, blood urea nitrogen, creatinine, and C-reactive protein by using a Piccolo point-of-care analyzer and BioChemistry Panel Plus analyzer discs (Abaxis).

\section{Histopathology and immunohistochemistry}

Necropsy was performed on all subjects. Tissue samples of all major organs were collected for histopathologic and immunohistochemical (IHC) examination, immersion-fixed in 10\% neutral buffered formalin, and processed for histopathology, as previously described (20). For IHC examination, specific anti-MARV VP40 protein rabbit primary antibody (Integrated BioTherapeutics) was used to detect MARV antigen. The secondary antibody used was biotinylated goat anti-rabbit IgG (Vector Laboratories), and LSAB2 streptavidin-horseradish peroxidase (Dako) was used to visualize antigen. Tissue sections were processed using the Dako Autostainer. Slides were developed with Dako diaminobenzidine chromogen and counterstained with hematoxylin. Non-immune rabbit IgG primary antibody was used as a negative control.

\section{MR191-N neutralization analysis for the presence of potential virus escape mutant}

Briefly, Vero E6 cells were seeded into six-well plates to generate a confluent monolayer on the day of inoculation. Neutralization assays were performed with serial dilutions of MR191-N prepared in Dulbecco's modified Eagle's medium and incubated with 100 PFU of MARV in a total volume of $200 \mu \mathrm{l}$ at $37^{\circ} \mathrm{C}$ for $60 \mathrm{~min}$; controls with no mAb were included (102 $\pm 8 \mathrm{PFU} ; n=6$ ). Medium was removed from cells, the mAb-virus mixture was added to duplicate wells, and plates were incubated for $60 \mathrm{~min}$ at $37^{\circ} \mathrm{C}$. The mixture was removed from the cells, and $2 \mathrm{ml}$ of $0.9 \%$ agarose in Eagle's minimum essential medium with 5\% fetal bovine serum was overlaid onto each of the wells. Cells were observed 5 to $7 \mathrm{dpi}$, and plaques were visualized and counted using neutral red stain.

\section{Deep sequencing analysis of RNA genome of MARV seed stock and NHP isolate}

To analyze the potential for MR191-N escape mutants, virus was isolated (Passage 1; Vero E6) from the 15-dpi sample of MARV Tx-5 and the original stock of MARV-Angola. Briefly, viral RNA was isolated from a TRIzol LS (Invitrogen)/sample mixture using a Direct-zol RNA MiniPrep (Zymo Research) according to the manufacturer's instructions. About $150 \mathrm{ng}$ of purified RNA was used to make complementary DNA using the Ovation RNA-Seq 2.0 kit (NuGEN), and this, in turn, was used for the preparation of the doublestranded DNA library, using the Encore Ion Torrent library prep kit. Sequencing was performed by the UTMB Molecular Core on the Ion Torrent using 318-v2 deep sequencing chips. Sequence analysis was performed using SeqMan NGen software (DNASTAR) on the basis of unpaired analysis of 125-base pair overlaps. 


\section{Statistical analysis}

Mantel-Cox test was used for analysis of differences in survival.

\section{Supplementary Material}

Refer to Web version on PubMed Central for supplementary material.

\section{Acknowledgments}

We thank V. Klimyuk and Y. Gleba for access to the magnICON expression system, Kentucky BioProcessing for their assistance, the staff of the UTMB Animal Resources Center for animal husbandry, the UTMB Research Histopathology Core for assistance with tissue processing, and the UTMB Galveston National Laboratory Molecular Core for preparing and running deep sequencing libraries.

Funding: This work was supported by the Department of Health and Human Services and NIH grants AI082744 (to L.Z.), AI109762 (to L.Z.), U19AI109711 (to T.W.G. and J.E.C.), and UC7AI094660 for BSL-4 operations support of the Galveston National Laboratory.

\section{REFERENCES AND NOTES}

1. Sanchez, A., Feldmann, H., Geisbert, TW. Filoviridae: Marburg and Ebola viruses. In: Knipe, DM., Howley, PM., editors. Fields Virology. Lippincott Williams \& Wilkins; 2013. p. 923-956.

2. Leitenberg, M., Zilinskas, RA. The Soviet Biological Weapons Program: A History. Harvard Univ. Press; 2012.

3. Ecker DM, Jones SD, Levine HL. The therapeutic monoclonal antibody market. MAbs. 2015; 7:914. [PubMed: 25529996]

4. Casadevall A, Scharff MD. Return to the past: The case for antibody-based therapies in infectious diseases. Clin Infect Dis. 1995; 21:150-161. [PubMed: 7578724]

5. Zeitlin L, Cone RA, Moench TR, Whaley KJ. Preventing infectious disease with passive immunization. Microbes Infect. 2000; 2:701-708. [PubMed: 10884621]

6. Geisbert TW, Mire CE, Geisbert JB, Chan Y-P, Agans KN, Feldmann F, Fenton KA, Zhu Z, Dimitrov DS, Scott DP, Bossart KN, Feldmann H, Broder CC. Therapeutic treatment of Nipah virus infection in nonhuman primates with a neutralizing human monoclonal antibody. Sci Transl Med. 2014; 6:242ra282.

7. Bossart KN, Geisbert TW, Feldmann H, Zhu Z, Feldmann F, Geisbert JB, Yan L, Feng Y-R, Brining D, Scott D, Wang Y, Dimitrov AS, Callison J, Chan Y-P, Hickey AC, Dimitrov DS, Broder CC, Rockx B. A neutralizing human monoclonal antibody protects African green monkeys from Hendra virus challenge. Sci Transl Med. 2011; 3:105ra103.

8. Pettitt J, Zeitlin L, Kim DH, Working C, Johnson JC, Bohorov O, Bratcher B, Hiatt E, Hume SD, Johnson AK, Morton J, Pauly MH, Whaley KJ, Ingram MF, Zovanyi A, Heinrich M, Piper A, Zelko J, Olinger GG. Therapeutic intervention of Ebola virus infection in rhesus macaques with the MB-003 monoclonal antibody cocktail. Sci Transl Med. 2013; 5:199ra113.

9. Qiu X, Wong G, Audet J, Bello A, Fernando L, Alimonti JB, Fausther-Bovendo H, Wei H, Aviles J, Hiatt E, Johnson A, Morton J, Swope K, Bohorov O, Bohorova N, Goodman C, Kim D, Pauly MH, Velasco J, Pettitt J, Olinger GG, Whaley K, Xu B, Strong JE, Zeitlin L, Kobinger GP. Reversion of advanced Ebola virus disease in nonhuman primates with ZMapp. Nature. 2014; 514:47-53. [PubMed: 25171469]

10. Strohl WR. Antibody discovery: Sourcing of monoclonal antibody variable domains. Curr Drug Discov Technol. 2014; 11:3-19. [PubMed: 24168292]

11. Crowe JE Jr. Recent advances in the study of human antibody responses to influenza virus using optimized human hybridoma approaches. Vaccine. 2009; 27(suppl 6):G47-G51. [PubMed: 20006140]

12. Smith SA, de Alwis R, Kose N, Durbin AP, Whitehead SS, de Silva AM, Crowe JE Jr. Human monoclonal antibodies derived from memory B cells following live attenuated dengue virus 
vaccination or natural infection exhibit similar characteristics. J Infect Dis. 2013; 207:1898-1908. [PubMed: 23526830]

13. Smith SA, Silva LA, Fox JM, Flyak AI, Kose N, Sapparapu G, Khomadiak S, Ashbrook AW, Kahle KM, Fong RH, Swayne S, Doranz BJ, McGee CE, Heise MT, Pal P, Brien JD, Austin SK, Diamond MS, Dermody TS, Crowe JE Jr. Isolation and characterization of broad and ultrapotent human monoclonal antibodies with therapeutic activity against chikungunya virus. Cell Host Microbe. 2015; 18:86-95. [PubMed: 26159721]

14. Bornholdt ZA, Turner HL, Murin CD, Li W, Sok D, Souders CA, Piper AE, Goff A, Shamblin JD, Wollen SE, Sprague TR, Fusco ML, Pommert KBJ, Cavacini LA, Smith HL, Klempner M, Reimann KA, Krauland E, Gerngross TU, Wittrup KD, Saphire EO, Burton DR, Glass PJ, Ward $\mathrm{AB}$, Walker LM. Isolation of potent neutralizing antibodies from a survivor of the 2014 Ebola virus outbreak. Science. 2016; 351:1078-1083. [PubMed: 26912366]

15. Flyak AI, Ilinykh PA, Murin CD, Garron T, Shen X, Fusco ML, Hashiguchi T, Bornholdt ZA, Slaughter JC, Sapparapu G, Klages C, Ksiazek TG, Ward AB, Saphire EO, Bukreyev A, Crowe JE Jr. Mechanism of human antibody-mediated neutralization of Marburg virus. Cell. 2015; 160:893903. [PubMed: 25723164]

16. Giritch A, Marillonnet S, Engler C, van Eldik G, Botterman J, Klimyuk V, Gleba Y. Rapid highyield expression of full-size $\mathrm{IgG}$ antibodies in plants coinfected with noncompeting viral vectors. Proc Natl Acad Sci USA. 2006; 103:14701-14706. [PubMed: 16973752]

17. Cross RW, Fenton KA, Geisbert JB, Ebihara H, Mire CE, Geisbert TW. Comparison of the pathogenesis of the Angola and Ravn strains of Marburg virus in the outbred guinea pig model. J Infect Dis. 2015; 212(suppl 2):S258-S270. [PubMed: 26092858]

18. Ursic-Bedoya R, Mire CE, Robbins M, Geisbert JB, Judge A, MacLachlan I, Geisbert TW. Protection against lethal Marburg virus infection mediated by lipid encapsulated small interfering RNA. J Infect Dis. 2014; 209:562-570. [PubMed: 23990568]

19. Mire CE, Geisbert JB, Versteeg KM, Mamaeva N, Agans KN, Geisbert TW, Connor JH. A singlevector, single-injection trivalent filovirus vaccine: Proof of concept study in outbred guinea pigs. $\mathrm{J}$ Infect Dis. 2015; 212(suppl 2):S384-S388. [PubMed: 25957964]

20. Thi EP, Mire CE, Ursic-Bedoya R, Geisbert JB, Lee ACH, Agans KN, Robbins M, Deer DJ, Fenton KA, MacLachlan I, Geisbert TW. Marburg virus infection in nonhuman primates: Therapeutic treatment by lipid-encapsulated siRNA. Sci Transl Med. 2014; 6:250ra116.

21. Geisbert TW, Daddario-DiCaprio KM, Geisbert JB, Young HA, Formenty P, Fritz EA, Larsen T, Hensley LE. Marburg virus Angola infection of rhesus macaques: Pathogenesis and treatment with recombinant nematode anticoagulant protein c2. J Infect Dis. 2007; 196(suppl 2):S372-S381. [PubMed: 17940973]

22. Olinger GG Jr, Pettitt J, Kim D, Working C, Bohorov O, Bratcher B, Hiatt E, Hume SD, Johnson AK, Morton J, Pauly M, Whaley KJ, Lear CM, Biggins JE, Scully C, Hensley L, Zeitlin L. Delayed treatment of Ebola virus infection with plant-derived monoclonal antibodies provides protection in rhesus macaques. Proc Natl Acad Sci USA. 2012; 109:18030-18035. [PubMed: 23071322]

23. Johnson ED, Johnson BK, Silverstein D, Tukei P, Geisbert TW, Sanchez AN, Jahrling PB. Characterization of a new Marburg virus isolated from a 1987 fatal case in Kenya. Arch Virol Suppl. 1996; 11:101-114. [PubMed: 8800792]

24. Jahrling PB, Geisbert J, Swearengen JR, Jaax GP, Lewis T, Huggins JW, Schmidt JJ, LeDuc JW, Peters CJ. Passive immunization of Ebola virus-infected cynomolgus monkeys with immunoglobulin from hyperimmune horses. Arch Virol Suppl. 1996; 11:135-140. [PubMed: 8800795]

25. Jahrling PB, Geisbert JB, Swearengen JR, Larsen T, Geisbert TW. Ebola hemorrhagic fever: Evaluation of passive immunotherapy in nonhuman primates. J Infect Dis. 2007; 196(suppl 2):S400-S403. [PubMed: 17940976]

26. Oswald WB, Geisbert TW, Davis KJ, Geisbert JB, Sullivan NJ, Jahrling PB, Parren PWHI, Burton DR. Neutralizing antibody fails to impact the course of Ebola virus infection in monkeys. PLOS Pathog. 2007; 3:e9. [PubMed: 17238286] 
27. Dye JM, Herbert AS, Kuehne AI, Barth JF, Muhammad MA, Zak SE, Ortiz RA, Prugar LI, Pratt WD. Postexposure antibody prophylaxis protects nonhuman primates from filovirus disease. Proc Natl Acad Sci USA. 2012; 109:5034-5039. [PubMed: 22411795]

28. Schmaljohn AL. Protective antiviral antibodies that lack neutralizing activity: Precedents and evolution of concepts. Curr HIV Res. 2013; 11:345-353. [PubMed: 24191933]

29. Corti D, Misasi J, Mulangu S, Stanley DA, Kanekiyo M, Wollen S, Ploquin A, Doria-Rose NA, Staupe RP, Bailey M, Shi W, Choe M, Marcus H, Thompson EA, Cagigi A, Silacci C, FernandezRodriguez B, Perez L, Sallusto F, Vanzetta F, Agatic G, Cameroni E, Kisalu N, Gordon I, Ledgerwood JE, Mascola JR, Graham BS, Muyembe-Tamfun J-J, Trefry JC, Lanzavecchia A, Sullivan NJ. Protective monotherapy against lethal Ebola virus infection by a potently neutralizing antibody. Science. 2016; 351:1339-1342. [PubMed: 26917593]

30. American Academy of Pediatrics Committee on Infectious Diseases; American Academy of Pediatrics Bronchiolitis Guidelines Committee. Updated guidance for palivizumab prophylaxis among infants and young children at increased risk of hospitalization for respiratory syncytial virus infection. Pediatrics. 2014; 134:e820-e638.

31. Geisbert TW, Strong JE, Feldmann H. Considerations in the use of nonhuman primate models of Ebola virus and Marburg virus infection. J Infect Dis. 2015; 212(suppl 2):S91-S97. [PubMed: 26063223]

32. Zeitlin L, Bohorov O, Bohorova N, Hiatt A, Kim DH, Pauly MH, Velasco J, Whaley KJ, Barnard DL, Bates JT, Crowe JE Jr, Piedra PA, Gilbert BE. Prophylactic and therapeutic testing of Nicotiana-derived RSV-neutralizing human monoclonal antibodies in the cotton rat model. MAbs. 2013; 5:263-269. [PubMed: 23396091]

33. Hiatt A, Bohorova N, Bohorov O, Goodman C, Kim D, Pauly MH, Velasco J, Whaley KJ, Piedra PA, Gilbert BE, Zeitlin L. Glycan variants of a respiratory syncytial virus antibody with enhanced effector function and in vivo efficacy. Proc Natl Acad Sci USA. 2014; 111:5992-5997. [PubMed: 24711420]

34. Zeitlin L, Geisbert JB, Deer DJ, Fenton KA, Bohorov O, Bohorova N, Goodman C, Kim D, Hiatt A, Pauly MH, Velasco J, Whaley KJ, Altmann F, Gruber C, Steinkellner H, Honko AN, Kuehne AI, Aman MJ, Sahandi S, Enterlein S, Zhan X, Enria D, Geisbert TW. Monoclonal antibody therapy for Junin virus infection. Proc Natl Acad Sci USA. 2016; 113:4458-4463. [PubMed: 27044104]

35. Zeitlin L, Pettitt J, Scully C, Bohorova N, Kim D, Pauly M, Hiatt A, Ngo L, Steinkellner H, Whaley KJ, Olinger GG. Enhanced potency of a fucose-free monoclonal antibody being developed as an Ebola virus immunoprotectant. Proc Natl Acad Sci USA. 2011; 108:20690-20694. [PubMed: 22143789]

36. Daddario-DiCaprio KM, Geisbert TW, Ströher U, Geisbert JB, Grolla A, Fritz EA, Fernando L, Kagan E, Jahrling PB, Hensley LE, Jones SM, Feldmann H. Postexposure protection against Marburg haemorrhagic fever with recombinant vesicular stomatitis virus vectors in non-human primates: An efficacy assessment. Lancet. 2006; 367:1399-1404. [PubMed: 16650649] 
Guinea pig-adapted MARV-Angola

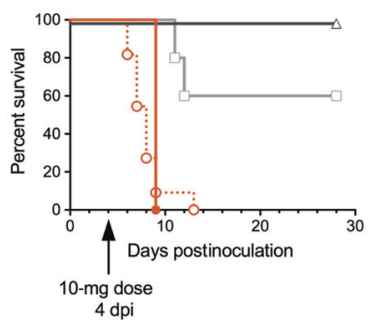

C

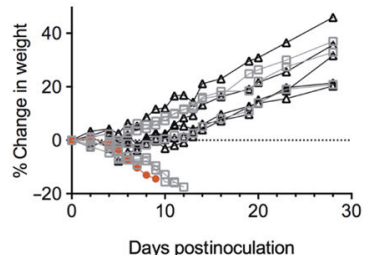

B

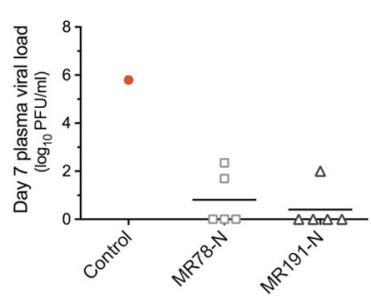

D

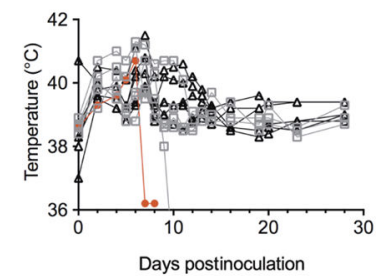

Guinea pig-adapted RAVV

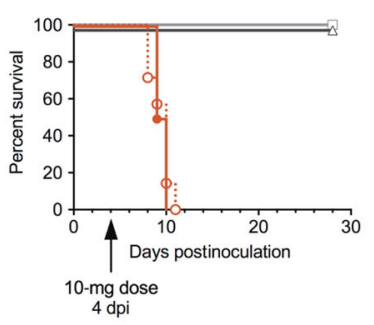

G

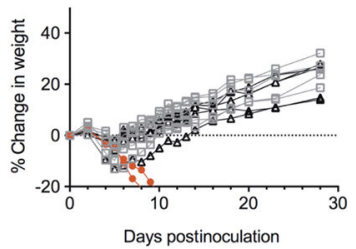

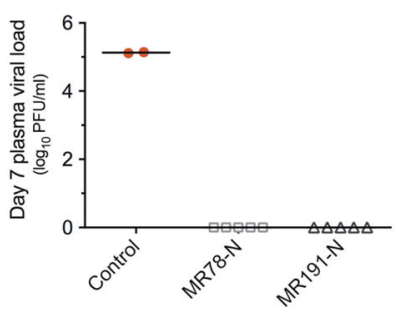

$\leftarrow$ MR191-N

$\square$ MR78-N

- Control

. O. Historical controls

Fig. 1. Therapeutic protection of guinea pigs inoculated with GPA MARV or GPA RAVV and treated 4 dpi with a single dose of $\mathrm{mAb}$

Guinea pigs received 1000 PFU of GPA MARV or RAVV intramuscularly and a 10-mg dose of mAb intraperitoneally 4 dpi $[n=5$ per treatment group, $n=1$ for phosphate-buffered saline (PBS)-treated MARV control, and $n=2$ for PBS-treated RAVV control]. (A) MARV: Kaplan-Meier survival plot. Historical controls represent animals $[n=11$; mean time to death $(\mathrm{MTD})=8.0 \pm 1.9 \mathrm{dpi}$ inoculated by the same route with the same stock of virus. (B) Plasma viral load 7 dpi as determined by plaque assay. (C) Percent change in weight. (D) Body temperature. (E) RAVV: Kaplan-Meier survival plot. Historical controls represent animals $(n=7$; MTD $=9.4 \pm 1.1 \mathrm{dpi})$ inoculated by the same route with the same stock of virus. (F) Plasma viral load 7 dpi as determined by plaque assay. (G) Percent change in weight. Body temperature was not monitored for RAVV-inoculated animals. 
A

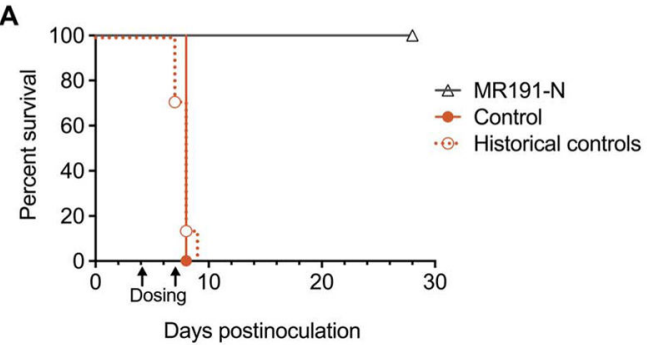

C

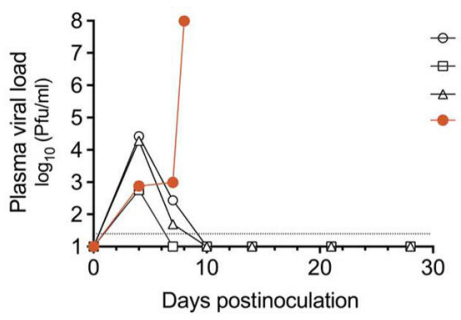

B

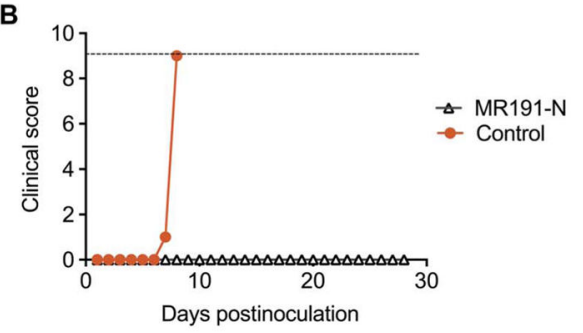

D

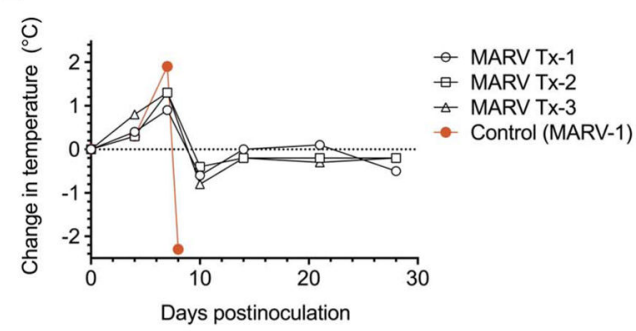

Fig. 2. Therapeutic protection of NHPs inoculated with MARV and treated 4 and 7 dpi with MR191-N

NHPs received 1050 PFU of MARV intramuscularly and a dose of mAb $(50 \mathrm{mg} / \mathrm{kg})$ intravenously 4 and 7 dpi ( $n=3$ treated animals and $n=1$ untreated control). (A) KaplanMeier survival plot. Arrows indicate day of $\mathrm{mAb}$ dosing. Historical controls represent animals $(n=10$; MTD $=7.9 \pm 0.6 \mathrm{dpi}$ ) inoculated by the same route by the same stock of virus. (B) Clinical score. The dashed line indicates clinical score threshold for euthanasia. (C) Viral load. Viral titer in plasma was determined by plaque assay. The dotted line indicates the limit of detection (25 PFU/ml). (D) Change in body temperature. 
A

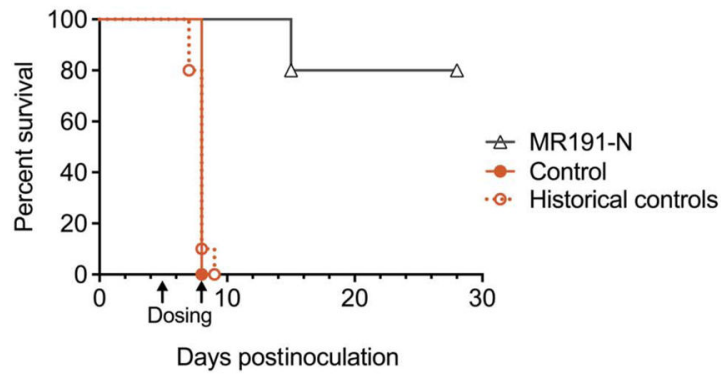

C

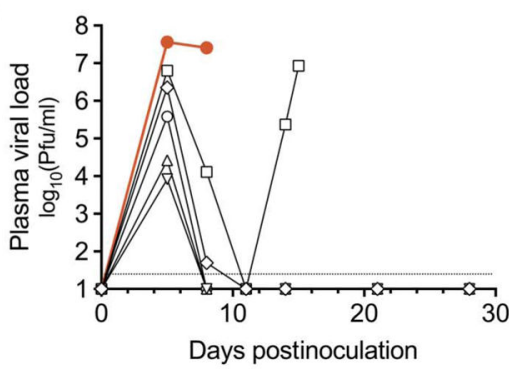

E

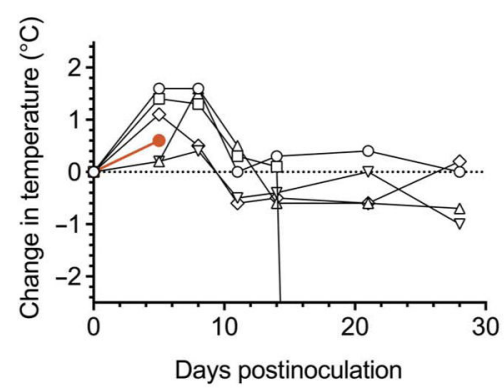

B

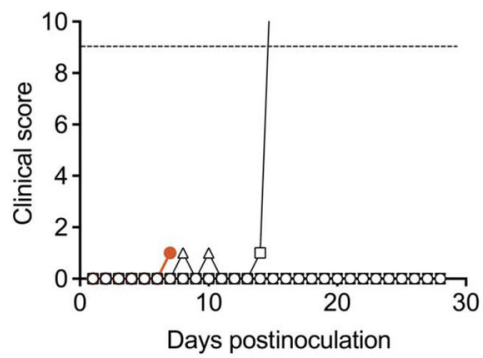

D

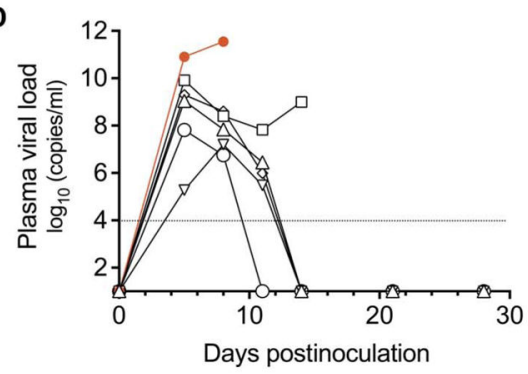

-o- MARV Tx-4

ㅁ- MARV Tx-5

$\triangle$ MARV Tx-6

$\rightarrow$ MARV Tx-7

$\diamond$ MARV TX-8

$\rightarrow$ Control (MARV-2)

Fig. 3. Therapeutic protection of NHPs inoculated with MARV and treated 5 and 8 dpi with MR191-N

NHPs received 1240 PFU of MARV intramuscularly and a dose of mAb (50 mg/kg) intravenously 5 and 8 dpi ( $n=5$ treated animals and $n=1$ untreated control). (A) KaplanMeier survival plot. Arrows indicate day of $\mathrm{mAb}$ dosing. Historical controls represent animals inoculated by the same route by the same stock of virus $(n=10$; MTD $=7.9 \pm 0.6$ dpi). (B) Clinical score. Dashed line indicates clinical score threshold for euthanasia. (C) Plasma viral load as determined by plaque assay. The dotted line indicates the limit of detection (25 PFU/ml). (D) Plasma viral load as detected by RT-qPCR. (E) Change in body temperature. 
A
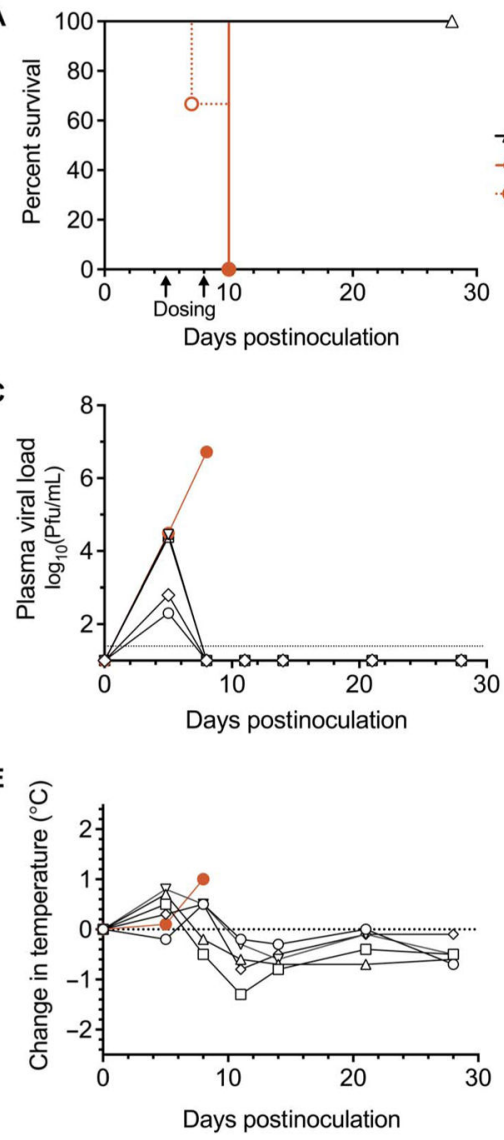

B

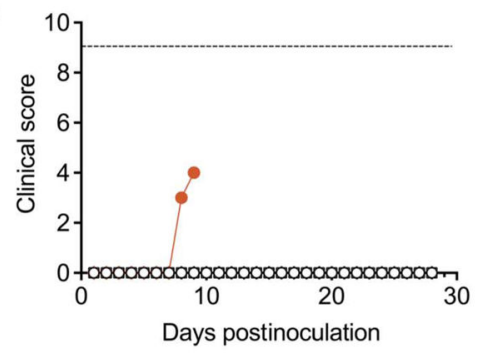

D

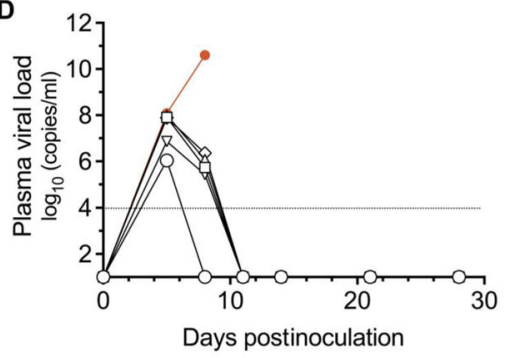

- - RAV T Tx-1

- - RAVV Tx-2

$\triangle$ RAVV Tx-3

$\rightarrow$ RAV T Tx-4

$\checkmark$ RAVV Tx-5

- Control (RAVV-1)

Fig. 4. Therapeutic protection of NHPs inoculated with RAVV and treated 5 and 8 dpi with MR191-N

NHPs received 1100 PFU of RAVV intramuscularly and a dose of mAb (50 mg/kg) intravenously 5 and 8 dpi ( $n=5$ treated animals and $n=1$ untreated control). (A) KaplanMeier survival plot. Arrows indicate day of $\mathrm{mAb}$ dosing. Historical controls represent animals inoculated by the same route by the same stock of virus $(n=3 ; \mathrm{MTD}=9.0 \pm 1.7$ dpi). (B) Clinical score. Dashed line indicates clinical score threshold for euthanasia. (C) Plasma viral load as determined by plaque assay. The dotted line indicates the limit of detection (25 PFU/ml). (D) Plasma viral load as detected by RT-qPCR. (E) Change in body temperature. 